\title{
Efeito da variação do gás de proteção no perfil de tensões residuais do aço inoxidável UNS S32304 soldado pelo processo TIG
}

\author{
Machado, C. S.C. ${ }^{1}$; Milagre, M.X. ${ }^{2}$; Orlando, M. T. D. ${ }^{3}$; Rossi, J.L. ${ }^{4}$; Luz, T.S. ${ }^{5}$; Macêdo, \\ M.C.S. ${ }^{6}$; Chagas, J.N. ${ }^{7}$ \\ 1,2 Programa de Pós-Graduação em Engenharia Mecânica, Universidade Federal do Espírito Santo, Vitória, ES, Brasil \\ 3 Departamento de Engenharia Mecânica, Universidade Federal do Espírito Santo, Vitória, ES, Brasil \\ 4 Doutor do Instituto de Pesquisas Energéticas e Nucleares, IPEN, São Paulo, São Paulo, Brasil \\ 5,6 Departamento de Engenharia Mecânica, Universidade Federal do Espírito Santo, Vitória, ES, Brasil \\ 7 Graduando em Engenharia Mecânica, Universidade Federal do Espírito Santo, Vitória, ES, Brasil
}

\begin{abstract}
Resumo
Tensões residuais podem ser muito prejudiciais ao desempenho de um componente, tornando sua quantificação e avaliação extremamente uteis. A difração de raio-X é um método de análise não destrutivo que permite avaliar as tensões sem comprometer o material. Neste trabalho, tiras de aço duplex UNS S32304 com 1,8mm de espessura foram cortadas nas dimensões $36 \times 72 \mathrm{~mm}$ e soldadas de modo autógeno através do processo TIG. Produziram-se dois tipos de amostras variando-se o gás de proteção a saber: mistura de argônio $98 \%$ e nitrogênio $2 \%$ e argônio $99.995 \%$. Utilizou-se um difratômetro com geometria Bragg-Brentano, fonte de radiação CuKa $(\langle\lambda\rangle=1,5419 \AA)$. A técnica $\operatorname{sen}^{2} \psi$ foi empregada para determinar a tensão residual da fase austenita no ângulo $2 \theta=146.22^{\circ}$. Os resultados mostram um estado de tensões residuais trativo nas proximidades da zona fundida, chegando a um estado compressivo em regiões distantes. A análise comparativa dos perfis de tensão residual revela que a amostra soldada apenas com argônio apresenta menor tensão residual trativa na zona fundida.
\end{abstract}

Palavras chaves: Tensão residual; Aço inoxidável duplex; Soldagem TIG; Difração de raio-X.

\section{Introdução}

Os aços inoxidáveis duplex possuem uma microestrutura bifásica, em quantidade equivalente de ferrita e austenita, no qual cada fase contribui com as propriedades finais deste aço, aliando resistência mecânica e resistência à corrosão [1,2,3]. Durante o processo de soldagem de tais aços, o material é submetido a uma série de ciclos térmicos que podem modificar a microestrutura do aço na zona fundida (ZF) e na zona termicamente afetada (ZTA). As altas temperaturas atingidas durante a soldagem geram gradientes de temperatura que favorecem a precipitação de fases deletérias (nitretos de cromo, por exemplo), afetando a fração volumétrica e gerando tensões residuais [3,4]. Tensões residuais são aquelas existentes em um corpo sólido quando este não está sob a ação de forças externas [5] e surgem devido a deformações não uniformes que podem ser de origem térmica, mecânica ou química. A figura 1 apresenta um padrão típico de tensões residuais longitudinais macroscópicos encontrados em chapas finas soldadas. Tem-se o valor máximo de tensão trativa no cordão de solda que é reduzido à medida que se vai distanciando da região central até que a tensão se torne compressiva, para manter o equilíbrio dos carregamentos internos, considerando-se que as tensões são constantes ao longo da espessura $[6,7,8]$.

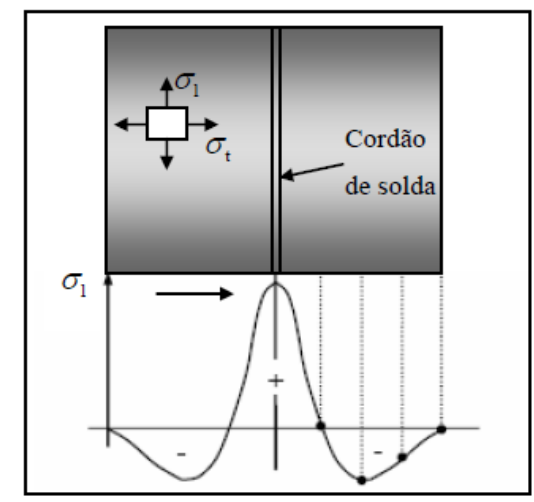

Figura 1: Esquema do comportamento das tensões residuais nas vizinhanças de uma união por soldagem de chapas finas [7]. 
Mesmo quando aparece em uma fina camada superficial, a tensão residual pode influenciar significativamente o desempenho funcional da peça. Tensões compressivas são preferíveis, já que tendem a diminuir as tensões de tração aplicadas externamente e a fechar trincas superficiais [9]. Quando influenciam negativamente, essas tensões potencializam diversos problemas como formação de trincas e maior tendência a fratura frágil, levando a redução da vida útil do componente além de comprometer seu comportamento [10]. A análise de tensão residual por difração de raio- $X$ em materiais cristalinos é baseada na determinação da deformação elástica do retículo, através do perfil de difração obtido com feixe monocromático de raio-X. Neste trabalho compara-se o perfil de tensões residuais da fase austenita, plano (420) de amostras de aço inoxidável duplex soldado pelo processo TIG, utilizando dois diferentes gases de proteção: argônio e mistura de argônio e $2 \%$ de nitrogênio.

\section{Materiais e métodos}

Tiras de aço inoxidável duplex UNS S32304 com $1,8 \mathrm{~mm}$ de espessura foram cortadas com auxílio de máquina de corte com lubrificação constante, para evitar a influência de tensões oriundas do corte, nas dimensões $36 \times 72 \mathrm{~mm}$. A tabela 1 traz a composição química fornecida pelo fabricante. Os corpos de prova produzidos foram soldados aos pares de forma autógena pelo processo TIG utilizando corrente alternada e polaridade direta. A corrente média, tensão e velocidade empregados foram 143A, 13V, $35 \mathrm{~cm} / \mathrm{min}$, respectivamente. Variou-se o gás de proteção, no qual uma das amostras foi soldada utilizando apenas argônio comercial e outra uma mistura de argônio e $2 \%$ de nitrogênio. A vazão de gás em ambos os casos foi de $10 \mathrm{l} / \mathrm{min}$. Utilizou-se a mesma variação de composição para o gás de purga. A tabela 2 apresenta as amostras produzidas destinadas a medição da tensão residual. A figura 2 traz os corpos de prova cortados e após a realização da soldagem.

Tabela 2. Identificação das amostras utilizadas

\begin{tabular}{cccc}
\hline Gás de proteção & $\mathrm{Ar}+2 \% \mathrm{~N}_{2}$ & $\mathrm{Ar}$ & Não soldada \\
\hline Identificação & $\mathrm{T}_{\mathrm{AN}}$ & $\mathrm{T}_{\mathrm{A}}$ & $\mathrm{T}_{\mathrm{CR}}$ \\
\hline
\end{tabular}

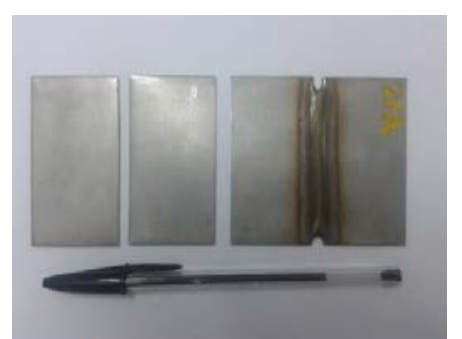

Figura 2: Corpos de prova antes e após soldagem

Tabela 1. Composição química do aço utilizado UNS S32304
A determinação da fração volumétrica de ferrita foi realizada utilizando um ferritoscópio. Foram realizadas 20 medidas de maneira aleatória no material como recebido e a mesma quantidade em cada região das amostras soldadas (MB, ZF e ZTA). Para avaliar a influência do gás de proteção na tensão residual os corpos de prova soldados foram submetidos a um polimento eletrolítico prévio, no qual uma fina camada superficial da região a ser analisada foi removida, a fim de limpar a superfície permitindo a medição de tensões residuais oriundas apenas do processo de soldagem. $\mathrm{O}$ polimento foi realizado com uma solução $25 \%$ de $\mathrm{H}_{2} \mathrm{SO}_{4}$ a $3 \mathrm{~V}$ durante $10 \mathrm{~min}$. As medidas de raio- $\mathrm{x}$ foram realizadas transversalmente ao cordão de solda ao longo das três regiões: metal base (MB), zona termicamente afetada (ZTA) e zona fundida (ZF), conforme figura 3. Para a amostra como recebida apenas um ponto central foi selecionado para análise.

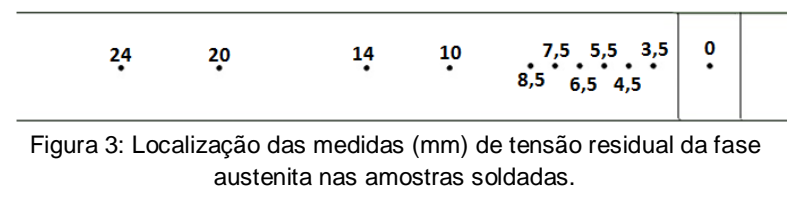

A medida da tensão residual na fase austenita, plano (420), foi realizada pela técnica de difração de raios-X, seguindo a norma SAE HS-784 [11]. As amostras foram avaliadas através de difratogramas gerados em difratômetro de raios- $x$, marca Rigaku, com geometria Bragg-Brentano, fonte de radiação CuKa $(\langle\lambda\rangle=$ $1,5419 \AA \AA)$, fenda de divergência de $0.05 \mathrm{~mm}$, fenda de divergência horizontal de $10 \mathrm{~mm}$, fenda de espalhamento de $1 / 2^{\circ}$, fenda receptora $0,3 \mathrm{~mm}$ e passos angulares de $0,04^{\circ}$. A tensão e a corrente empregada foi de $40 \mathrm{kV}$ e $20 \mathrm{~mA}$, respectivamente. Cinco ângulos $\psi$ foram utilizados $0^{\circ}, 15^{\circ}, 30^{\circ}, 45^{\circ}, 60^{\circ}$ no intervalo angular $2 \theta$ de $142^{\circ}$ a $152^{\circ}$. As intensidades difratadas com varredura $2 \theta$ para cada $\psi$ foram coletadas. Utilizou-se o software FityK para construção dos difratogramas, ajustes das curvas e localização dos picos [12]. A função escolhida para ajuste foi a Pearson 7A. Plotou-se o gráfico da deformação $x \sin ^{2} \psi$, o qual permitiu calcular os valores de tensão residual. $O$ coeficiente de Poisson e o módulo de elasticidade utilizados foram obtidos na literatura, sendo 0,305 e $190 \mathrm{GPa}$, respectivamente [13].

\section{Resultados e discussão}

\subsection{Fração volumétrica da ferrita}

A tabela 3 apresenta os resultados encontrados para a fase ferrita através do ferritoscópio. Observa-se o desbalanceamento de fases provocado pelo processo de soldagem.

\begin{tabular}{|c|c|c|c|c|c|c|c|c|c|c|c|c|}
\hline Elemento & $\mathrm{Cr}$ & $\mathrm{Ni}$ & Mo & Mn & Si & C & $\mathbf{P}$ & $\mathbf{S}$ & $\mathrm{Ti}$ & $\mathrm{Cu}$ & Co & $\mathbf{N}$ \\
\hline Teor (\%) & 22,20 & 3,52 & 0,255 & 1,40 & 0,250 & 0,016 & 0,023 & 0,001 & 0,0041 & 0,4171 & 0,09 & 0,1030 \\
\hline
\end{tabular}


Tabela 3. Fração volumétrica de ferrita

\begin{tabular}{cccc}
\hline & ZF & ZTA & MB \\
\hline $\mathbf{T}_{\mathrm{AN}}(\%)$ & $(60 \pm 1)$ & $(43,0 \pm 0,2)$ & $(47,4 \pm 0,3)$ \\
\hline $\mathbf{T}_{\mathrm{A}}(\%)$ & $(61 \pm 1)$ & $(42,2 \pm 0,2)$ & $(46,5 \pm 0,3)$ \\
\hline $\mathbf{T}_{\mathrm{CR}}(\%)$ & & $(50,0 \pm 0,3)$ & \\
\hline
\end{tabular}

A adição de 1-10\% em volume de nitrogênio ao gás de proteção durante um processo de soldagem tem a finalidade de aumentar o teor de nitrogênio na ZF e manter o seu teor original na ZTA. Como o nitrogênio é um elemento austenitizante, o seu aumento acarreta em uma fração volumétrica maior de austenita na ZF [14]. Entretanto, considerando as incertezas, observase que o comportamento das amostras soldadas em diferentes condições é semelhante: na zona fundida a fração de ferrita é elevada, há uma queda no valor na zona termicamente afetada e ocorre um aumento do teor no metal base.

\subsection{Medida de tensão residual}

\subsubsection{Amostra como recebida $\left(T_{C R}\right)$}

A figura 4 apresenta o gráfico $\varepsilon \times \operatorname{sen}^{2} \Psi$ para o material como recebido. Observa-se que a inclinação da curva é decrescente, indicando que a tensão residual tem caráter compressivo, cujo valor é $(-248 \pm 11) \mathrm{MPa}$.

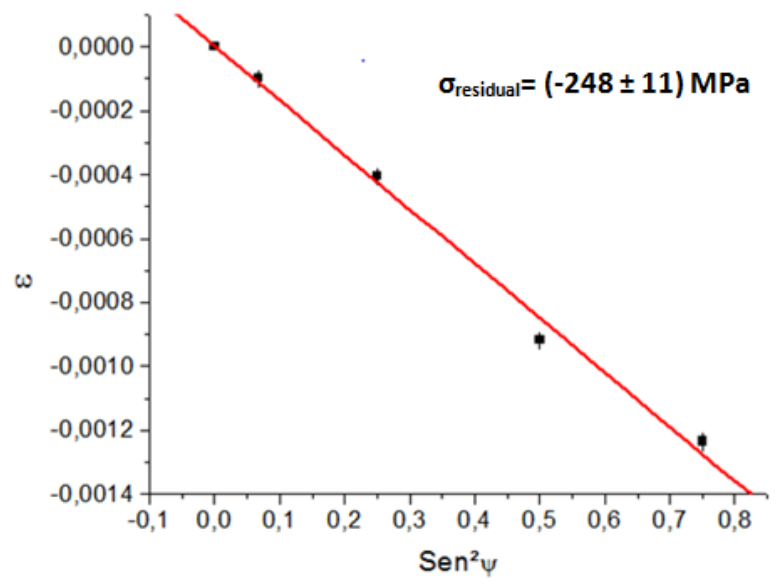

Figura 4. Gráfico da deformação em função da variação do ângulo $\Psi$.

\subsubsection{Amostra Soldada}

A figura 5 apresenta o perfil de tensões encontrado para as diferentes amostras. Observa-se que na amostra soldada apenas com argônio, a ZF apresentou menor tensão residual trativa, comparada a amostra soldada com gás de proteção composto pela mistura argônio e nitrogênio.
A partir da ZTA, há um decréscimo no valor de tensão para ambas as amostras, até que se atinjam tensões residuais compressivas. Observa-se ainda que a amostra $\mathrm{T}_{\mathrm{AN}}$ tem valores compressivos a partir de $10 \mathrm{~mm}$ de distância em relação ao centro da zona fundida, enquanto que a amostra $\mathrm{T}_{\mathrm{A}}$ somente a partir de $14 \mathrm{~mm}$.

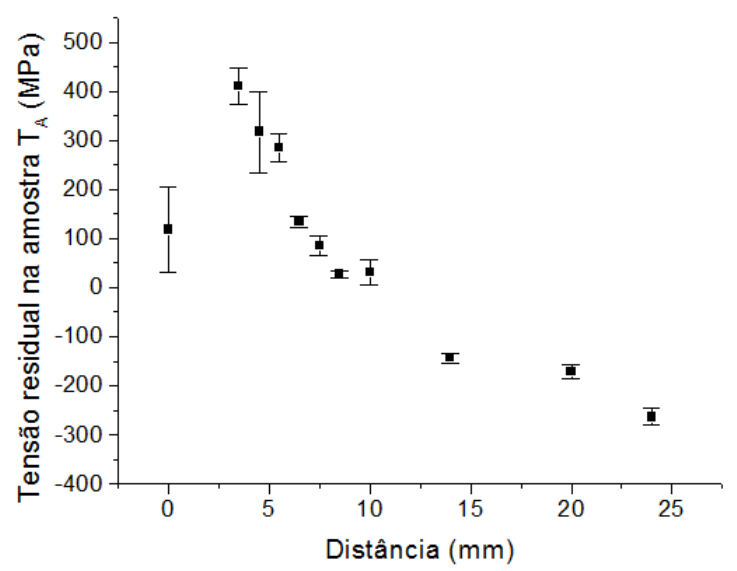

(a)

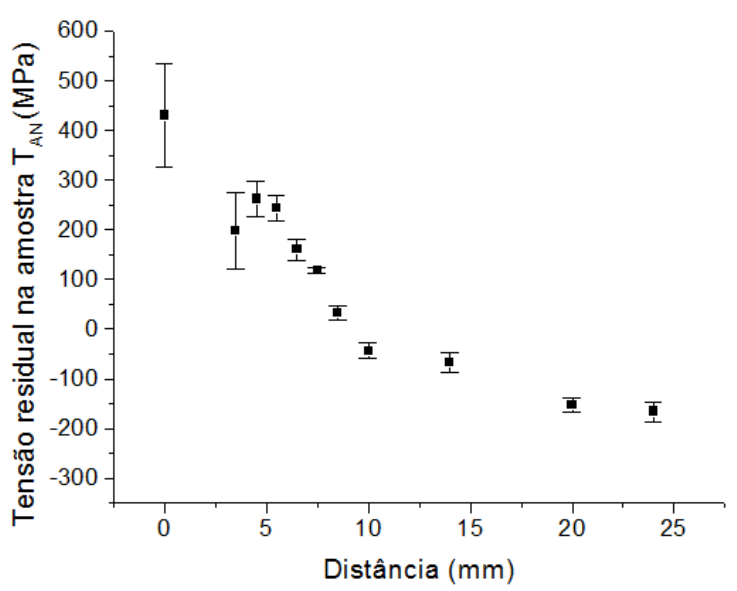

(b)

Figura 5. Perfil de tensão residual medido na fase austenita em amostras soldadas (a) $\mathrm{T}_{\mathrm{A}}$ com argônio; (b) $\mathrm{T}_{\mathrm{AN}}$ com mistura gasosa argônio $+2 \%$ nitrogênio.

Comparando-se o perfil obtido de tensões residuais da amostra $T_{A N}$ com a fração volumétrica da fase ferrita na ZF e ZTA (regiões afetadas pelo desbalanceamento de fase) da mesma amostra, parece existir uma relação entre o teor de ferrita e as tensões. Na zona fundida há maior teor de ferrita e as tensões são trativas e elevadas. A medida que se afasta da zona fundida, há uma redução no teor de ferrita, bem como no comportamento das tensões observadas.

Embora o valor de tensão obtido na zona fundida da amostra $T_{A}$ seja divergente da amostra $T_{A N}$, não se pode afirmar que ambas as amostras apresentam tendências diferentes sendo necessária a realização de 


\section{Blucher Proceedings \\ IV Workshop of Applied Crystallography to \\ Materials Science and Engineering}

mais medidas a fim de obter reprodutibilidade dos dados.

\section{Conclusões}

Os resultados apresentados para as chapas nas condições aqui estudadas apresentaram valores de tensão residual trativa na zona fundida e termicamente afetada e compressiva em regiões mais afastadas do cordão.

Observa-se que o valor de tensão residual na zona fundida é menor na amostra soldada com argônio. O perfil gerado na amostra soldada com argônio e nitrogênio sugere a existência de relação entre a fração volumétrica e as tensões residuais.

\section{Agradecimentos}

Os autores agradecem à CAPES - Pró-Estratégia 2224/2012 pela bolsa de Mestrado e ao Sr. Yukio Nishida pelo apoio na caracterização das amostras.

\section{Referências}

[1] Westin E. M. Pitting corrosion resistance of gta welded lean duplex stainless steel. Welding in the world. 2010; volume(54): página 308 e 321.

[2] Santos C. Z. Estudo da tensão residual através de difração de raios $x$ em aço inoxidável duplex submetido a diferentes tratamentos térmicos [mestrado]. Vitória: Universidade Federal do Espírito Santo; 2012.

[3] Palácio F. O. Estudo do efeito de parâmetros do processo GTAW pulsado na resistência à corrosão intergranular e por pite do aço inoxidável duplex UNS S32304 [mestrado]. Vitória: Universidade Federal do Espírito Santo; 2011.

[4] Silva C.C. Avaliação das tensões residuais de soldagem em tubulações de pequeno diâmetro usadas em refinaria de Petróleo. [Mestrado]. Fortaleza: Universidade Federal do Ceará; 2007.
[5] Totten, G., Howes, M., Inoue, T. Handbook of Residual Stress and Deformation of Steel. ASM International. 2002, p.11

[6] Okumura, T; Taniguchi, C. Engenharia de soldagem e aplicações. Rio de Janeiro: Editora LTC; 1982.

[7] Rodrigues, L.D. Medição de tensões residuais em tubos visando a determinação de esforços em dutos enterrados. [Mestrado]. Rio de Janeiro: Pontifícia Universidade Católica; 2007.

[8] Withers, P. J., Bhadeshia, H. K. D. H. Residual stress part 1 - Measurement techniques. Materials Science and Technology. 2001; volume (17), pp. 355365.

[9] Farias, A. Estudo da tensão residual através de difração de raios $x$ em aço inoxidável duplex submetido a diferentes tratamentos térmicos. [Mestrado]. São Paulo: Escola Politécnica da Universidade de São Paulo; 2009.

[10] Modenesi, P. J.; Marques, P. V.; Santos, D. B. Introdução à Metalurgia da Soldagem. Universidade Federal de Minas Gerais - Departamento de Engenharia Metalúrgica e de Materiais. 2012. [acesso em 12 mar. 2014] Disponível em: http://demet.eng.ufmg.br/wpcontent/uploads/2012/10/metalurgia.pdf>.

[11] SAE. HS-784: Residual stress measurement by $x-$ ray diffraction. Pennsylvania, 2003.

[12] Wojdyr, M. Fityk: a general-purpose peak fitting program J. Appl. Cryst. 43, 1126 (2010)

[13] Johansson J., Oden M., Zeng X.H. Evolution of the residual stress state in a Duplex stainless steel during loading. Acta Metallurgica.1999; volume (47), pp 26692684.

[14] Ramírez-londoño, A.J. Estudo da Precipitação de nitreto de cromo e fase sigma por simulação térmica da zona afetada pelo calor na soldagem multipasse de aços inoxidáveis duplex. [Mestrado]. São Paulo: Escola Politécnica da Universidade de São Paulo; 1997 